\title{
Additional non-sentinel lymph node metastases in early oral cancer patients with positive sentinel lymph nodes
}

\author{
Inne J. Den Toom ${ }^{1,5} \cdot$ Elisabeth Bloemena $^{2,4} \cdot$ Stijn van Weert $^{1} \cdot$ K. Hakki Karagozoglu ${ }^{2}$. \\ Otto S. Hoekstra ${ }^{3} \cdot$ Remco de Bree $^{1,5}$
}

Received: 2 June 2016/ Accepted: 19 August 2016/Published online: 25 August 2016

(c) The Author(s) 2016. This article is published with open access at Springerlink.com

\begin{abstract}
To determine risk factors for additional nonsentinel lymph node metastases in neck dissection specimens of patients with early stage oral cancer and a positive sentinel lymph node biopsy (SLNB). A retrospective analysis of 36 previously untreated SLNB positive patients in our institution and investigation of currently available literature of positive SLNB patients in early stage oral cancer was done. Degree of metastatic involvement [classified as isolated tumor cells (ITC), micro- and macrometastasis] of the sentinel lymph node (SLN), the status of other SLNs, and additional non-SLN metastases in neck dissection specimens were analyzed. Of 27 studies, comprising 511 patients with positive SLNs, the pooled prevalence of non-SLN metastasis in patients with positive SLNs was $31 \%$. Non-SLN metastases were detected (available from 9 studies) in 13, 20, and $40 \%$ of patients with ITC, micro-, and macrometastasis in the SLN,
\end{abstract}

Remco de Bree

r.debree@umcutrecht.nl

1 Department of Otolaryngology-Head and Neck Surgery, VU University Medical Center, P.O. Box 7057, 1007 MB Amsterdam, The Netherlands

2 Department of Oral and Maxillofacial Surgery/Oral Pathology, VU University Medical Center/Academic Center for Dentistry (ACTA) Amsterdam, P.O. Box 7057, 1007 MB Amsterdam, The Netherlands

3 Department of Radiology and Nuclear Medicine, VU University Medical Center, P.O. Box 7057, 1007 MB Amsterdam, The Netherlands

4 Department of Pathology, VU University Medical Center, P.O. Box 7057, 1007 MB Amsterdam, The Netherlands

5 Department of Head and Neck Surgical Oncology, UMC Utrecht Cancer Center, University Medical Center Utrecht, P.O. Box 85500, 3508 GA Utrecht, The Netherlands respectively. The probability of non-SLN metastasis seems to be higher in the case of more than one positive SLN (29 vs. $24 \%$ ), the absence of negative SLNs (40 vs. $19 \%$ ), and a positive SLN ratio of more than $50 \%$ (38 vs. $19 \%$ ). Additional non-SLN metastases were found in $31 \%$ of neck dissections following positive SLNB. The presence of multiple positive SLNs, the absence of negative SLNs, and a positive SLN ratio of more than $50 \%$ may be predictive factors for non-SLN metastases. Classification of SLNs into ITC, micro-, and macrometastasis in the future SLNB studies is important to answer the question if treatment of the neck is always needed after positive SLNB.

Keywords Sentinel lymph node biopsy $\cdot$ Mouth neoplasms · Neck dissection - Lymph nodes - Lymphatic metastasis · Neoplasm micrometastasis

\section{Introduction}

Sentinel lymph node biopsy (SLNB) has been introduced for the detection of occult lymph node metastasis in patients with early stage oral cancer. Observational trials (with only neck dissection after positive SLNB) have demonstrated that SLNB is a sensitive method in the detection of occult cervical lymph node metastases. A recent meta-analysis found a pooled sensitivity of $91 \%$ (95\% CI 84-95\%) and a negative predictive value ranging from 92 to $98 \%$ when follow-up was used as reference standard [1]. Long-term follow-up studies showed that SLNB is a safe procedure $[2,3]$. Recently, we reported a sensitivity of $93 \%$ and a negative predictive value of $97 \%$ of SLNB in our first 90 early oral cancer patients [4].

Metastatic tumor deposits can be categorized as isolated tumor cells (ITC), micrometastasis, and macrometastasis. 
ITCs are generally defined as tumor deposits $\leq 0.2 \mathrm{~mm}$ (pNOi+), micro- ( $\mathrm{pN} 1 \mathrm{mi})$, and macrometastases $(\mathrm{pN} 1)$ as tumor deposits of $0.21-2.0 \mathrm{~mm}$ and $>2.0 \mathrm{~mm}$, respectively. In addition, for ITC, more specific histopathological characteristics have been described: no contact with vessel or lymph sinus wall, no extravasation, no extravascular stromal reaction, and no extravascular tumor cell proliferation [5].

So far, the same strategy has been used in the case of sentinel nodes with ITCs, micro-, and macrometastases, which means a (selective) neck dissection. Broglie et al. found significantly higher hazard ratios in overall disease specific and disease free survival for micrometastases and macrometastases, whereas ITCs were significant determinants for disease specific survival compared with SLN negative patients [6].

A report of a European multicenter study on 109 oral squamous cell carcinoma patients with positive SLNB showed additional (non-SLN) metastases in $34.4 \%$ of the neck dissection specimens [7].

The recent update of this trial demonstrated a statistically lower overall survival for micro- and macrometastases compared with ITC [8]. If a reliable nomogram to predict non-SLN metastases based on degree of metastatic tumor deposits in SLNs can be developed, SLNB might be a therapeutic rather than just a diagnostic procedure, i.e., avoiding subsequent tumor-negative neck dissections. The aim of the present retrospective study and the literature review is to analyze risk factors for the presence of non-SLN metastases in SLNB positive early oral cancer patients.

\section{Materials and methods}

\section{Retrospective study}

From February 2007 until October 2014, 139 consecutive patients with cT1-2N0 squamous cell carcinomas of the oral cavity or oropharynx underwent transoral excision and SLNB. After approval of the Institutional Review Board and Ethics Committee, informed consent was obtained until SLNB was performed as standard procedure in our institution. SLNB was performed according to the EANM/ SENT joint practice guidelines [9]. A detailed description of the procedure in our institution had been described previously [4].

A positive SLNB was followed by (selective) neck dissection in 36/37 (97\%) patients (one patient with ITC was treated by radiotherapy only, which was indicated for adverse histopathological findings of the primary tumor).

The neck dissection specimen was histopathologically examined for additional lymph node metastases using a routine procedure (no step-serial sectioning and immunohistochemistry). The presence and localization (level) of additional lymph node metastasis were scored for each patient.

The numbers of tumor positive ( 1 vs. $>1)$ and negative $(0$ vs. $\geq 1)$ SLNs and their ratio $(\leq 50$ vs. $>50 \%)$ were scored for each patient.

\section{Literature analysis}

Studies included in recent meta-analyses [1, 10] were analyzed for data on the degree of metastatic involvement of SLN, the status of other SLNs, and additional non-SLN metastases in neck dissection specimens following positive SLNB. In addition, references were explored to identify other relevant articles. If presented (or could be subtracted from the data provided), the rate of positive non-SLN was scored for ITC, micrometastasis, macrometastasis, number of positive SLNs (1 vs. $>1$ ), number of negative SLNs (0 vs. $\geq 1$ ), and their ratio ratio ( $\leq 50 \mathrm{vs.}>50 \%$ ) per patient.

Due to low numbers, no statistical analyses were performed.

\section{Results}

\section{Retrospective study}

At least one histopathologically positive SLN was found in $36 / 139$ (26\%) of patients, yielding a total of 43 positive SLNs. One patient with a paramedian T1 tongue tumor was diagnosed with bilateral positive SLNs. In both neck sides, the largest tumor deposit in the positive SLN, respectively, ITC, and macrometastasis, was separately investigated. The remaining patients with at least two positive SLNs had only unilateral metastasis, and the largest tumor deposit was taken for evaluation and follow-up of the neck. Overall, we analyzed 36 patients with 37 SLN positive neck sides, subdivided into 7 necks with ITC, 14 with micro-, and 16 with macrometastasis (Tables 1, 2).

In none of the SLNs with ITC based on size, extravasation, extravascular stromal reaction or extravascular tumor cell proliferation were found, but all these SLNs had contact with lymph sinus wall.

In 6/36 (17\%) patients who underwent a subsequent neck dissection, additional lymph node metastases were found. All patients had T2 tumors and the SLN had contained a macrometastasis (Table 3).

Additional non-SLN metastases were found in level I $(n=3)$, level III $(n=6)$, level IV $(n=1)$, and level V $(n=1)$. In one patient, non-SLN metastasis was restricted to the same level as the positive SLN, in one patient in adjacent and non-adjacent levels, and in 4 patients, nonSLN metastasis were only found in non-adjacent levels. 
Table 1 Data of demographic and tumor-related patient characteristics

\begin{tabular}{llll}
\hline Characteristic & Overall $(\%)$ & \multicolumn{2}{l}{ Status of SLNB } \\
\cline { 3 - 4 } & & Negative $(\%)$ & Positive (\%) \\
\hline Patients, $n(\%)$ & $139(100 \%)$ & $103(74 \%)$ & $36(26 \%)$ \\
Gender, $n(\%)$ & & $54(52 \%)$ & $17(47 \%)$ \\
Male & $71(51 \%)$ & $49(48 \%)$ & $19(53 \%)$ \\
Female & $68(49 \%)$ & $60(27-85)$ & $62(29-86)$ \\
Median age (year) (range) & $60(27-86)$ & & $24(66 \%)$ \\
Tumor location, $n(\%)$ & & $62(60 \%)$ & $9(25 \%)$ \\
Tongue & $86(61 \%)$ & $6(30 \%)$ & 0 \\
Floor of mouth & $40(29 \%)$ & $2(2 \%)$ & $2(6 \%)$ \\
Buccal mucosa & $6(4 \%)$ & $2(2 \%)$ & $1(3 \%)$ \\
Inferior alveolar process & $4(3 \%)$ & & $16(44 \%)$ \\
Soft palate & $3(2 \%)$ & $81(79 \%)$ & $20(56 \%)$ \\
Clinical T stage, $n(\%)$ & $97(70 \%)$ & $22(21 \%)$ & $43(13 \%)$ \\
T1 & $42(30 \%)$ & $285(87 \%)$ & $36(1-98)$ \\
T2 & 328 & $36(1-102)$ & \\
No of SLNs & $36(1-102)$ & & \\
Follow-up, $(m)$ (range) & & & \\
Observation time (months) & & & \\
\hline
\end{tabular}

SLNB sentinel lymph node biopsy, SLNs sentinel lymph nodes
Table 2 Prevalence of ITC, micrometastasis, and macrometastasis in positive SLNs

\begin{tabular}{lrccc}
\hline Study & All & \multicolumn{1}{l}{ ITC } & \multicolumn{1}{l}{ Micro } & \multicolumn{1}{l}{ Macro } \\
\hline Barzan [11] & $2^{\mathrm{a}}$ & $0(0 \%)$ & $1(50 \%)$ & $1(50 \%)$ \\
Mozillo [12] & 4 & $0(0 \%)$ & $4(100 \%)$ & $0(0 \%)$ \\
Stoeckli [13] & 9 & $1(11 \%)$ & $5(56 \%)$ & $3(33 \%)$ \\
Keski-Säntti [14] & 2 & $0(0 \%)$ & $1(50 \%)$ & $1(50 \%)$ \\
Bilde [15] & 11 & $3(27 \%)$ & $6(55 \%)$ & $2(18 \%)$ \\
Atula [16] & 34 & $5(15 \%)$ & $14(41 \%)$ & $15(44 \%)$ \\
Kovacs [17] & 9 & $0(0 \%)$ & $3(33 \%)$ & $6(67 \%)$ \\
Alkureishi [18] & $42^{\mathrm{b}}$ & $0(0 \%)$ & $10(24 \%)$ & $32(76 \%)$ \\
Burcia [19] & 38 & $14(37 \%)$ & $15(39 \%)$ & $9(24 \%)$ \\
Terada [20] & 5 & $0(0 \%)$ & $3(60 \%)$ & $2(40 \%)$ \\
Broglie [6] & 42 & $10(24 \%)$ & $19(45 \%)$ & $13(31 \%)$ \\
Present study & 36 & $6(16 \%)$ & $14(39 \%)$ & $16(44 \%)$ \\
Total & 234 & $39(17 \%)$ & $95(41 \%)$ & $100(43 \%)$ \\
\hline
\end{tabular}

ITC isolated tumor cells; micro micrometastasis; macro macrometastasis; SLN sentinel lymph node

a Only results of cNO early oral cancer

b Definition of micrometastasis: only detected by step-serial sectioning and/or immunohistochemistry

If $>1$ SLN was positive, $2 / 5$ (40\%) of the patients had additional neck metastases compared to 4/31 (13\%) in patients with a single positive SLN. In 2/13 (15\%) patients with solely positive SLN(s), additional non-SLN metastases were found (vs. $17 \%$ if synchronous presence of negative SLNs was present). If more positive than negative
SLNs were present ( $>50 \%$ SLN positive), additional nonSLN metastases were found in 3/14 (21\%) patients compared to $3 / 22(14 \%)$ if a similar or higher number of negative than positive SLNs were found (Table 3).

\section{Review of the literature}

Eleven studies [6, 11-20] had categorized the size of tumor deposits in SLNs. Including the data from our study, ITC was present in $17 \%$ of 234 patients (range 0-37\%), micrometastasis in $41 \%$ (19-100 \%), and macrometastasis in $43 \%(0-76 \%)$ (Table 3). Additional non-SLN metastases were mainly found in levels I, II, and III and sometimes in level IV or V [7, 13, 15, 16, 21, 22]. The pooled prevalence of non-SLN metastasis in patients with positive SLN(s) of this study and 26 other studies $[6,7,11-17,21-37]$ was $31 \%(156 / 511)$.

The pooled probability of non-SLN metastasis in this present study and 8 other studies $[6,11,13,15-17,23,25]$ was $13 \%$ (4/32), $20 \%$ (11/55), and $40 \%$ (19/49) for ITC, micro-, and macrometastases, respectively. This probability was $26 \%(37 / 144)$ for micro- and macrometastases combined.

Including our results, a higher pooled prevalence for additional non-SLN metastases had been found when $>1$ positive SLNs were present (29 vs. $24 \%)$ $[11,13,16,22-24,30]$, the absence of negative SLNs (40 vs. $19 \%)[13,15,16,22-24,30,33,37]$, and in the case of a positive SLN ratio of more than $50 \%$ (38 vs. $19 \%$ ) [13, 16, 22-24, 30, 33]. Results are shown in Table 3. 


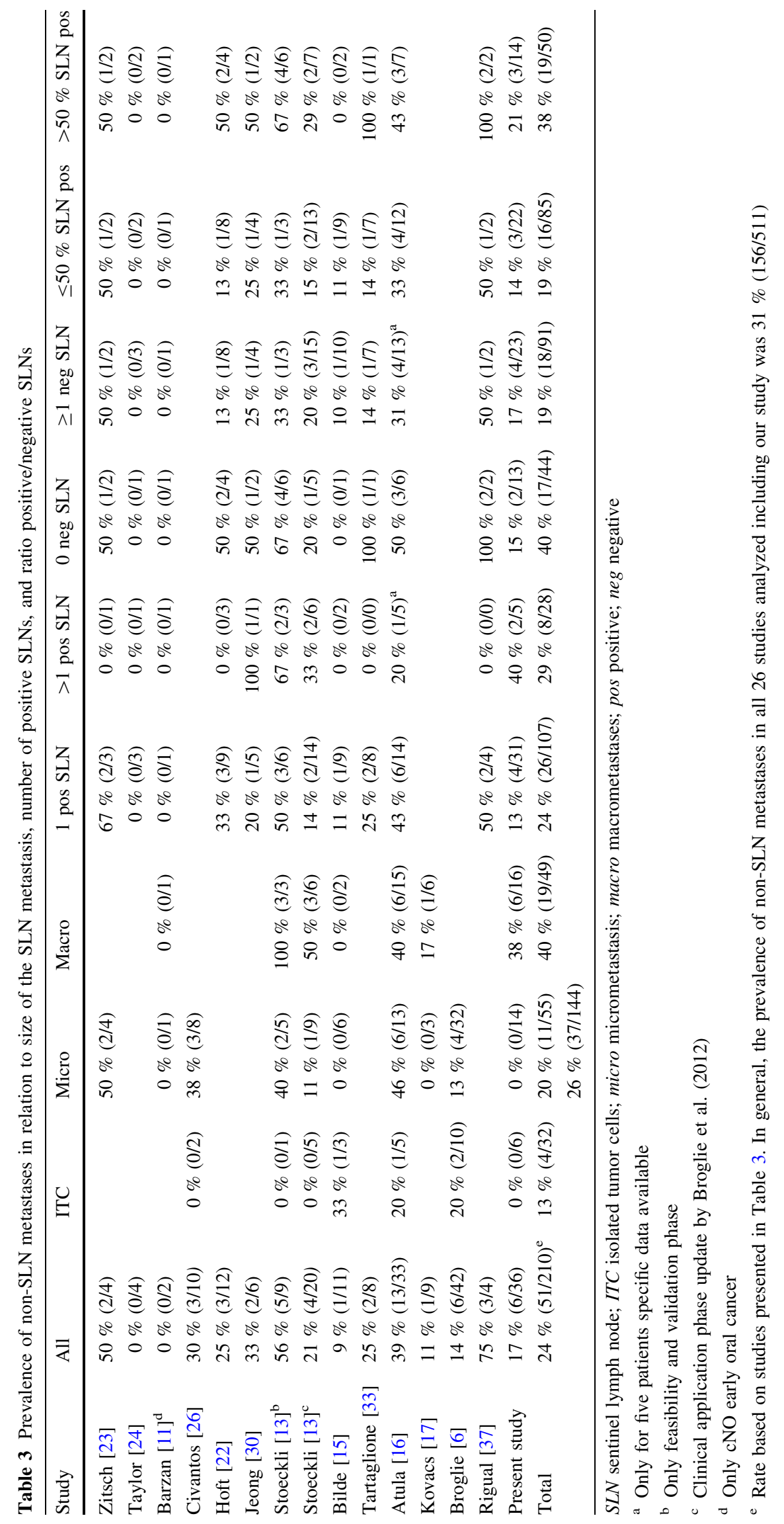




\section{Discussion}

Patients with positive SLNB undergo generally subsequent (completion) neck dissection, because there is no reliable means of detecting or predicting non-SLN metastasis. SLNB is associated with significant less morbidity than elective neck dissection and identification of patients who do not benefit from subsequent neck dissection may decrease this morbidity even further [38].

The prediction of the presence of non-SLN metastasis in the neck after positive SLNB can theoretically be improved in two ways: dividing the tumor deposits in SLNs into subgroups or adding other predictive factors in a risk profile.

Combining this study with our analysis of the literature, we found an inverse relation between the size of tumor deposits in the SLN and the probability of a non-SLN: $13 \%$ for ITC, $20 \%$ for micrometastasis, and $40 \%$ for macrometastasis. Since the prevalence of non-SLN metastasis in the neck dissection specimen following ITC in SLNs is substantial, in early stage oral cancer, one cannot refrain from neck dissection after any category of positive SLNB. When patients with a low risk of non-SLN metastasis can be identified, a wait and scan policy using USgFNAC may be justified [39].

The commonly used definition of isolated tumor cells is based on size $(0.2 \mathrm{~mm}$ or less) rather than designation of the metastatic tumor deposit. ITC is then considered to be a small micrometastasis "waiting to grow" (precursor of micrometastasis) with a risk these necks with SLNs containing ITC may also harbor micro- or macrometastases [40]. In this study, all ITCs based on size had the same morphologic features: no extravasation, extravascular stromal reaction or extravascular tumor cell proliferation, but all had contact with lymph sinus wall. Since these deposits seem to be real ITC, this latter feature is debatable.

Review of the literature revealed that only a limited number of small studies classified SLN tumor deposits in ITC, micrometastasis, and macrometastasis. The wide variety of rates of the different categories in our literature review may reflect the lack of uniformly used definitions.

Consequently, these numbers are too low to perform reliable statistical analyses on the risk of non-SLN metastases in these different tumor deposits in SLNs. To explore if patients with ITC or micrometastasis in SLNs need a subsequent neck dissection, it is important that all future studies report SLN metastases in these categories. Only, then, the question if SLNB can be used as treatment, and not only as diagnostic procedure, in patients selected by the type of tumor deposit in SLNs can be answered.

In breast cancer, SLNB is accepted as standard diagnostic technique for clinically node negative patients.
Complete axillary lymph node dissection is generally recommended if the SLNB is positive. Non-SLN metastases are detected in $35-50 \%$ of SLN positive patients. Only some series report that the prevalence of ITC and distinction between ITC and micrometastasis could be difficult [41, 42]. The reported rate of micrometastasis as the largest tumor deposit in SLN positive breast cancer patients varies considerably: from 24 to $93 \%$ [43]. In patients with tumor deposits in SLNs, the prevalences of ITC, micrometastasis, and macrometastasis are 7-16, 16-32, and 58-78\%, respectively. Non-SLN metastases are found in $0-13$, $12-27$, and $48-50 \%$ in patients with ITC, micro-, and macrometastases in SLNs, respectively [44-49].

Different nomograms in predicting non-SLN metastases in breast cancer patients with a positive SLNB have been developed, usually including the largest detected size of SLN metastasis and the proportion of involved SLNs among all removed SLNs [43]. The treatment strategy for micrometastasis in SLN is under debate. It has been suggested to refrain patients with ITC in their SLN from axillary lymph node dissection [44-46]. A recent review including 7151 breast cancer patients with positive SLNB in whom an axillary lymph node dissection was omitted revealed an axillary recurrence rate of $0.7 \%$ (range $0-7.1 \%$ ) for macrometastasis and $0.3 \%$ (range 0-3.4\%) for micrometastasis and ITC. Unfortunately, micrometastasis and ITC could not be analyzed separately, and details regarding adjuvant treatment were lacking in the majority of studies [50]. Since breast cancer patients are often treated with adjuvant systemic therapy, these strategies cannot easily be translated to early oral cancer patients who are usually treated with surgery as monotherapy.

A meta-analysis of predictive factors for non-SLN metastases in breast cancer patients with a positive SLN confirmed a high likelihood of non-SLN metastases for size of SLN metastasis of more than $2 \mathrm{~mm}$ [macrometastasis; odds ratio (OR) 4.22], extracapsular extension in the SLN (OR 4.10), one or less negative SLN (OR 2.66), more than one positive SLN (OR 2.60), tumor size $>2 \mathrm{~cm}$ (OR 2.41), a ratio of positive SLN of more than $50 \%$ (OR 2.25), and lymphovascular invasion (OR 2.24) [51]. Recently, the same authors developed a risk score based on these parameters [52].

In oral oncology, Gurney et al. [7] reported other predictive factors for the presence of non-SLN metastases in SLNB positive necks: tumor site (higher risk as the primary tumor was located at the posterior part of the oral cavity), increased stage (T2-4 stage at higher risk), and number of negative SLNs (lower risk in higher number of negative SLNs). In this study, all patients with non-SLN metastases had T2 oral squamous cell carcinoma. Although tumor thickness or depth of invasion [53] and molecular markers 
[54] has predictive value for the presence of (occult) lymph node metastasis, their role in predicting the presence of non-SLN metastasis in oral cancer patients with a positive SLNB is not known yet.

Our retrospective study suggests if both a positive SLN and a negative SLN are present the prevalence of non-SLN metastases seems nearly equal compared to patients with solely positive SLNs, in contrast to other studies (Table 3). Since distinguishing real SLNs from the second echelon nodes may be difficult [55], it can be anticipated that (some of) these negative SLNs may be, in fact, the second echelon nodes. If more positive than negative SLNs are present, the probability of non-SLN metastases seems to be higher, also in case of a ratio of positive SLNs of more than $50 \%$. Due to the low number of cases, statistical analysis could not be performed and more larger studies are needed to confirm these ideas.

A large multicenter study showed in $1 / 122$ neck dissections following positive SLNBs of early oral cancer non-SLN metastases in levels other than I-III [7]. These non-SLN metastases had been found in $15 \%$ of the patients in the same level, in $17 \%$ in an adjacent level, and in $2 \%$ in a non-adjacent level. In our retrospective study, all non-SLN metastases were found in levels I-IV except one in level V. In this latter patient, two positive SLNs and five additional non-SLNs were found. In $67 \%(4 / 6)$ of the patients, non-SLNs were only found in non-adjacent levels. If the future studies report on the level involved by nonSLN metastases, more tailored (super)selective neck dissections may be defined.

Analysis of the literature, including our present study, showed that additional non-SLN metastases were found in $31 \%$ of neck dissections following positive SLNB. Selected by tumor deposit, these percentages were $13 \%$ for ITC, $20 \%$ for micro-, and $40 \%$ for macrometastasis in SLNs. This prevalence may be underestimated, since, in most studies, non-SLNs are examined using routine histopathological examination without step-serial sectioning and immunohistochemistry. Studies on neck dissection specimens show that immunohistochemistry can reveal small metastases in $15 \%$ of the patients that remain undetected in routine H\&E staining [56].

Reporting other risk factors may be useful to develop a nomogram selecting SLNB positive patients for neck dissection and active surveillance or wait and scan follow-up. The presence of more than one positive SLN, the absence of negative SLNs (besides a positive SLN), and a positive SLN ratio of more than $50 \%$ may be predictive factors for non-SLN metastasis in SLNB positive patients. To this point, there is no well-argued reason to refrain from an additional neck dissection based on these risk factors or tumor size in the SLN. The presented data support the use of a selective neck dissection, when because of an SLNB positive neck an additional neck dissection is indicated.

\section{Compliance with ethical standards}

Ethical approval All procedures performed in studies involving human participants were in accordance with the ethical standards of the institutional and/or national research committee and with the 1964 Helsinki declaration and its later amendments or comparable ethical standards. For this type of study formal consent is not required.

Conflict of interest The authors declare that they have no conflict of interest.

Open Access This article is distributed under the terms of the Creative Commons Attribution 4.0 International License (http://crea tivecommons.org/licenses/by/4.0/), which permits unrestricted use, distribution, and reproduction in any medium, provided you give appropriate credit to the original author(s) and the source, provide a link to the Creative Commons license, and indicate if changes were made.

\section{References}

1. Govers TM, Hannink G, Merkx MA, Takes RP, Rovers MM (2013) Sentinel node biopsy for squamous cell carcinoma of the oral cavity and oropharynx: a diagnostic meta-analysis. Oral Oncol 49(8):726-732

2. Broglie MA, Haile SR, Stoeckli SJ (2011) Long-term experience in sentinel node biopsy for early oral and oropharyngeal squamous cell carcinoma. Ann Surg Oncol 18(10):2732-2738

3. Pedersen NJ, Jensen DH, Hedbäck N, Frendø M, Kiss K, Lelkaitis $\mathrm{G}$ et al (2015) Staging of early lymph node metastases with the sentinel lymph node technique and predictive factors in T1/T2 oral cavity cancer: a retrospective single-center study. Head Neck. doi:10.1002/hed.24153

4. Den Toom IJ, Heuveling DA, Flach GB, van Weert S, Karagozoglu KH, van Schie A et al (2015) Sentinel node biopsy for early-stage oral cavity cancer: the VU University Medical Center experience. Head Neck 37(4):573-578

5. Hermanek P, Hutter RV, Sobin LH, Wittekind C (1999) International Union Against Cancer. Classification of isolated tumor cells and micrometastasis. Cancer 86(12):2668-2673

6. Broglie MA, Haerle SK, Huber GF, Haile SR, Stoeckli SJ (2013) Occult metastases detected by sentinel node biopsy in patients with early oral and oropharyngeal squamous cell carcinomas: impact on survival. Head Neck 35(5):660-666

7. Gurney BA, Schilling C, Putcha V, Alkureishi LW, Alvarez AJ, Bakholdt $\mathrm{V}$ et al (2012) Implications of a positive sentinel node in oral squamous cell carcinoma. Head Neck 34(11):1580-1585

8. Schilling C, Stoeckli SJ, Haerle SK, Broglie MA, Huber GF, Sorensen JA et al (2015) Sentinel European Node Trial (SENT): 3 -years results of sentinel node biopsy in oral cancer. Eur $\mathbf{J}$ Cancer 51:2777-2784

9. Alkureishi LW, Burak Z, Alvarez JA, Ballinger J, Bilde A, Britten AJ et al (2009) European Association of Nuclear Medicine Oncology Committee; European Sentinel Node Biopsy Trial Committee. Joint practice guidelines for radionuclide lymphoscintigraphy for sentinel node localization in oral/oropharyngeal squamous cell carcinoma. Ann Surg Oncol 16(11):3190-3210

10. Thompson CF, St John MA, Lawson G, Grogan T, Elashoff D, Mendelsohn AH (2013) Diagnostic value of sentinel lymph node 
biopsy in head and neck cancer: a meta-analysis. Eur Arch Otorhinolaryngol 270(7):2115-2122

11. Barzan L, Sulfaro S, Alberti F, Politi D, Marus W, Pin M et al (2002) Gamma probe accuracy in detecting the sentinel lymph node in clinically N0 squamous cell carcinoma of the head and neck. Ann Otol Rhinol Laryngol 111(9):794-798

12. Mozzillo N, Chiesa F, Caracò C, Botti G, Lastoria S, Longo F et al (2004) Therapeutic implications of sentinel lymph node biopsy in the staging of oral cancer. Ann Surg Oncol 11(3 Suppl):263S-266S

13. Stoeckli SJ (2007) Sentinel node biopsy for oral and oropharyngeal squamous cell carcinoma of the head and neck. Laryngoscope 117(9):1539-1551

14. Keski-Säntti H, Kontio R, Leivo I, Törnwall J, Mätzke S, Mäkitie AA et al (2008) Sentinel lymph node biopsy as an alternative to wait and see policy in patients with small $\mathrm{T} 1$ oral cavity squamous cell carcinoma. Acta Otolaryngol 128(1):98-102

15. Bilde A, von Buchwald C, Therkildsen MH, Mortensen J, Kirkegaard J, Charabi B et al (2008) Need for intensive histopathologic analysis to determine lymph node metastases when using sentinel node biopsy in oral cancer. Laryngoscope 118(3):408-414

16. Atula T, Hunter KD, Cooper LA, Shoaib T, Ross GL, Soutar DS (2009) Micrometastases and isolated tumour cells in sentinel lymph nodes in oral and oropharyngeal squamous cell carcinoma. Eur J Surg Oncol 35(5):532-538

17. Kovács AF, Stefenelli U, Seitz O, Middendorp M, Diener J, Sader R et al (2009) Positive sentinel lymph nodes are a negative prognostic factor for survival in T1-2 oral/oropharyngeal cancer-a long-term study on 103 patients. Ann Surg Oncol 16(2):233-239

18. Alkureishi LW, Ross GL, Shoaib T, Soutar DS, Robertson AG, Thompson R et al (2010) Sentinel node biopsy in head and neck squamous cell cancer: 5-year follow-up of a European multicenter trial. Ann Surg Oncol 17(9):2459-2464

19. Burcia V, Costes V, Faillie JL, Gardiner Q, de Verbizier D, Cartier C et al (2010) Neck restaging with sentinel node biopsy in T1-T2N0 oral and oropharyngeal cancer: why and how? Otolaryngol Head Neck Surg 142(4):592-597

20. Terada A, Hasegawa Y, Yatabe Y, Hanai N, Ozawa T, Hirakawa $\mathrm{H}$ et al (2011) Follow-up after intraoperative sentinel node biopsy of N0 neck oral cancer patients. Eur Arch Otorhinolaryngol 268(3):429-435

21. Ross GL, Soutar DS, MacDonald DG, Shoaib T, Camilleri I, Roberton AG et al (2004) Sentinel node biopsy in head and neck cancer: preliminary results of a multicenter trial. Ann Surg Oncol 11(7):690-696

22. Höft S, Maune S, Muhle C, Brenner W, Czech N, Kampen WU et al (2004) Sentinel lymph-node biopsy in head and neck cancer. Br J Cancer 91(1):124-128

23. Zitsch RP 3rd, Todd DW, Renner GJ, Singh A (2000) Intraoperative radiolymphoscintigraphy for detection of occult nodal metastasis in patients with head and neck squamous cell carcinoma. Otolaryngol Head Neck Surg 122(5):662-666

24. Taylor RJ, Wahl RL, Sharma PK, Bradford CR, Terrell JE, Teknos TN et al (2001) Sentinel node localization in oral cavity and oropharynx squamous cell cancer. Arch Otolaryngol Head Neck Surg 127(8):970-974

25. Pitman KT, Johnson JT, Brown ML, Myers EN (2002) Sentinel lymph node biopsy in head and neck squamous cell carcinoma. Laryngoscope 112(12):2101-2113

26. Civantos FJ, Gomez C, Duque C, Pedroso F, Goodwin WJ, Weed DT et al (2003) Sentinel node biopsy in oral cavity cancer: correlation with PET scan and immunohistochemistry. Head Neck 25(1):1-9
27. Kontio R, Leivo I, Leppänen E, Atula T (2004) Sentinel lymph node biopsy in oral cavity squamous cell carcinoma without clinically evident metastasis. Head Neck 26(1):16-21

28. Thomsen JB, Sørensen JA, Grupe P, Krogdahl A (2005) Sentinel lymph node biopsy in oral cancer: validation of technique and clinical implications of added oblique planar lymphoscintigraphy and/or tomography. Acta Radiol 46(6):569-575

29. Rigual N, Douglas W, Lamonica D, Wiseman S, Cheney R, Hicks W Jr et al (2005) Sentinel lymph node biopsy: a rational approach for staging T2N0 oral cancer. Laryngoscope 115(12):2217-2220

30. Jeong HS, Baek CH, Son YI, Cho DY, Chung MK, Min JY et al (2006) Sentinel lymph node radiolocalization with $99 \mathrm{mTc}$ filtered tin colloid in clinically node-negative squamous cell carcinomas of the oral cavity. J Korean Med Sci 21(5):865-870

31. Civantos FJ, Moffat FL, Goodwin WJ (2006) Lymphatic mapping and sentinel lymphadenectomy for 106 head and neck lesions: contrasts between oral cavity and cutaneous malignancy. Laryngoscope 112(3 Pt 2 Suppl 109):1-15

32. Burns P, Foster A, Walshe P, O'Dwyer T (2009) Sentinel lymph node biopsy in node-negative squamous cell carcinoma of the oral cavity and oropharynx. J Laryngol Otol 123(4):439-443

33. Tartaglione G, Vigili MG, Rahimi S, Celebrini A, Pagan M, Lauro L et al (2008) The impact of superficial injections of radiocolloids and dynamic lymphoscintigraphy on sentinel node identification in oral cavity cancer: a same-day protocol. Nucl Med Commun 29(4):318-322

34. Civantos FJ, Zitsch RP, Schuller DE, Agrawal A, Smith RB, Nason R et al (2010) Sentinel lymph node biopsy accurately stages the regional lymph nodes for T1-T2 oral squamous cell carcinomas: results of a prospective multi-institutional trial. J Clin Oncol 28(8):1395-1400

35. Melkane AE, Mamelle G, Wycisk G, Temam S, Janot F, Casiraghi $\mathrm{O}$ et al (2012) Sentinel node biopsy in early oral squamous cell carcinomas: a 10-year experience. Laryngoscope 122(8):1782-1788

36. Yoshimoto S, Hasegawa Y, Matsuzuka T, Shiotani A, Takahashi $\mathrm{K}$, Kohno $\mathrm{N}$ et al (2012) Sentinel node biopsy for oral and laryngopharyngeal squamous cell carcinoma: a retrospective study of 177 patients in Japan. Auris Nasus Larynx 39(1):65-70

37. Rigual N, Loree T, Frustino J, Jayaprakash V, Cohan D, Sullivan $\mathrm{M}$ et al (2013) Sentinel node biopsy in lieu of neck dissection for staging oral cancer. JAMA Otolaryngol Head Neck Surg 139(8):779-782

38. Murer K, Huber GF, Haile SR, Stoeckli SJ (2011) Comparison of morbidity between sentinel node biopsy and elective neck dissection for treatment of the $\mathrm{n} 0$ neck in patients with oral squamous cell carcinoma. Head Neck 33(9):1260-1264

39. Flach GB, Tenhagen M, de Bree R, Brakenhoff RH, van der Waal I, Bloemena E et al (2013) Outcome of patients with early stage oral cancer managed by an observation strategy towards the N0 neck using ultrasound guided fine needle aspiration cytology: no survival difference as compared to elective neck dissection. Oral Oncol 49(2): 157-164

40. Thomsen JB, Sørensen JA, Krogdahl A (2005) Sentinel lymph nodes in cancer of the oral cavity-isolated tumour cells. J Oral Pathol Med 34(2):65-69

41. de Mascarel I, MacGrogan G, Debled M, Brouste V, Mauriac (2008) Distinction between isolated tumor cells and micrometastases in breast cancer: is it reliable and useful? Cancer 112(8): 1672-1678

42. Cserni G, Bianchi S, Boecker W, Decker T, Lacerda M, Rank F, Wells CA, European Working Group for Breast Screening Pathology (2005) Improving the reproducibility of diagnosing micrometastases and isolated tumor cells. Cancer 103(2):358-367 
43. Gur AS, Unal B, Johnson R, Ahrendt G, Bonaventura M, Gordon $P$ et al (2009) Predictive probability of four different breast cancer nomograms for nonsentinel axillary lymph node metastasis in positive sentinel node biopsy. J Am Coll Surg 208(2):229-235

44. Calhoun KE, Hansen NM, Turner RR, Giuliano AE (2005) Nonsentinel node metastases in breast cancer patients with isolated tumor cells in the sentinel node: implications for completion axillary node dissection. Am J Surg 190(4):588-591

45. van Rijk MC, Peterse JL, Nieweg OE, Oldenburg HS, Rutgers EJ, Kroon BB (2006) Additional axillary metastases and stage migration in breast cancer patients with micrometastases or submicrometastases in sentinel lymph nodes. Cancer 107(3):467-471

46. Reed J, Rosman M, Verbanac KM, Mannie A, Cheng Z, Tafra L (2009) Prognostic implications of isolated tumor cells and micrometastases in sentinel nodes of patients with invasive breast cancer: 10-year analysis of patients enrolled in the prospective East Carolina University/Anne Arundel Medical Center Sentinel Node Multicenter Study. J Am Coll Surg 208(3):333-340

47. van la Parra RF, Francissen CM, Peer PG, Ernst MF, de Roos WK, Van Zee KJ et al (2013) Assessment of the Memorial SloanKettering Cancer Center nomogram to predict sentinel lymph node metastases in a Dutch breast cancer population. Eur J Cancer 49(3):564-571

48. van Deurzen $\mathrm{CH}$, van Hillegersberg R, Hobbelink MG, Seldenrijk CA, Koelemij R, van Diest PJ (2007) Predictive value of tumor load in breast cancer sentinel lymph nodes for second echelon lymph node metastases. Cell Oncol 29(6):497-505

49. Hessman CJ, Naik AM, Kearney NM, Jensen AJ, Diggs BS, Troxell ML et al (2011) Comparative validation of online nomograms for predicting nonsentinel lymph node status in sentinel lymph node-positive breast cancer. Arch Surg 146(9):1035-1040

50. Francissen CM, Dings PJ, van Dalen T, Strobbe LJ, van Laarhoven HW, de Wilt JH (2012) Axillary recurrence after a tumorpositive sentinel lymph node biopsy without axillary treatment: a review of the literature. Ann Surg Oncol 19(13):4140-4149

51. van la Parra RF, Peer PG, Ernst MF, Bosscha K (2011) Metaanalysis of predictive factors for non-sentinel lymph node metastases in breast cancer patients with a positive SLN. Eur J Surg Oncol 37(4):290-299

52. van la Parra RF, Peer PG, de Roos WK, Ernst MF, de Wilt JH, Bosscha K (2014) A Simple risk score to predict the presence of non-sentinel lymph node metastases in breast cancer patients with a positive sentinel node. World J Surg 38(5):1070-1076

53. Huang SH, Hwang D, Lockwood G, Goldstein DP, O'Sullivan B (2009) Predictive value of tumor thickness for cervical lymphnode involvement in squamous cell carcinoma of the oral cavity: a meta-analysis of reported studies. Cancer 115:1489-1497

54. Leusink FK, van Es RJ, de Bree R, Baatenburg de Jong RJ, van Hooff SR, Holstege FC et al (2012) Novel diagnostic modalities for assessment of the clinically node-negative neck in oral squamous-cell carcinoma. Lancet Oncol 13:e554-e561

55. Flach GB, van Schie A, Witte BI, Olmos RA, Klop WM, Hoekstra OS et al (2014) Practice variation in defining sentinel lymph nodes on lymphoscintigrams in oral cancer patients. Eur $\mathbf{J}$ Nucl Med Mol Imaging 41(12):2249-2256

56. Rinaldo A, Devaney KO, Ferlito A (2004) Immunohistochemical studies in the identification of lymph node micrometastases in patients with squamous cell carcinoma of the head and neck. ORL J Otorhinolaryngol Relat Spec 66(1):38-41 